\title{
On possible changes in the calculation of parameters of transport technology of open pit mining with the use of autonomous heavy platforms
}

\author{
Dmitry Stenin* \\ T.F. Gorbachev Kuzbass State Technical University, Department of Vehicle Operation, 650000, \\ Kemerovo, 28 Vesennyaya st., Russian Federation
}

\begin{abstract}
Reducing the costs of the transport component, reaching up to $50 \%$ or more of the total cost of the mined coal, is an urgent task that does not require additional confirmation. Since the development of measures to improve the purely technical indicators of motor transport at open-pit mines is beyond the scope of the general study, we will limit ourselves to the search for technological solutions that can have a positive impact on the overall cost of production. This may include, for example, the search for solutions to reduce the duration of the transport cycle and optimization of its components. It is also necessary to study the possible changes in the indicators of the transport technology of open-pit mining when using classic open-pit dump trucks and autonomous heavy platforms (unmanned open-pit haul trucks). The article presents an analysis of existing technical and technological solutions and research on the use of unmanned transport technologies. It is established that the parameters of transport technology will change to some extent with the introduction of unmanned heavy platforms, which will inevitably lead both to the correction of the existing regulatory documentation, and a possible revision of the classical postulates of open-pit mining.
\end{abstract}

\section{Introduction}

In open-pit mining of coal deposits, wheeled types of transport are traditionally used - road and rail. Conveyor transport and hydraulic transport are not widespread for a number of reasons; for example, in Kuzbass the main limiting factor is climatic. As the depth of openpit mining increases, rail transport loses its advantages and its use becomes unprofitable. Therefore, in fact, the only type of transport currently in use is road transport. Transportation costs make up to $50 \%$ of the total cost of the mined coal. Therefore, any reduction of costs for the transport component is very urgent. A significant number of scientific works by both domestic and foreign scientists, which cannot be mentioned in a single article, are devoted to such issues; therefore, we will limit ourselves to a few [1-19]. Some of them are aimed at improving the conditions of movement of open-pit dump trucks

* Corresponding author: $\underline{\text { sdn.ea@ } @ \text { kuzstu.ru }}$ 
in terms of changing the parameters of quarry roads; some of them are aimed at studying the loading conditions with suggestions for its optimization; some of them are aimed at establishing the mutual influencing factors of excavator-automotive complexes' work. Recently some number of articles on research of open-cast mining technology with unmanned haul trucks (in some sources they are also called autonomous heavy platforms) have been noted. First of all, they concern the development of coal deposits; for Russia and Kuzbass in particular, these issues are very important because of the significant share of the coal industry in the list of extractive industries.

\section{Analysis of the state of the issue}

Apparently, the first works devoted to quarry unmanned vehicles date back to the mid-80s early 90 s of the last century [20-22]. It is logical that the first developers and researchers were specialists of large automobile concerns: Komatsu, Hitachi, etc. Further development of the work was aimed at creating the overall structure of the complex, providing the full functioning of quarry unmanned vehicles in the overall structure of the enterprise [23-34]. Figures 1-4 show the structural diagrams of the equipment operation, presented in the mentioned articles.

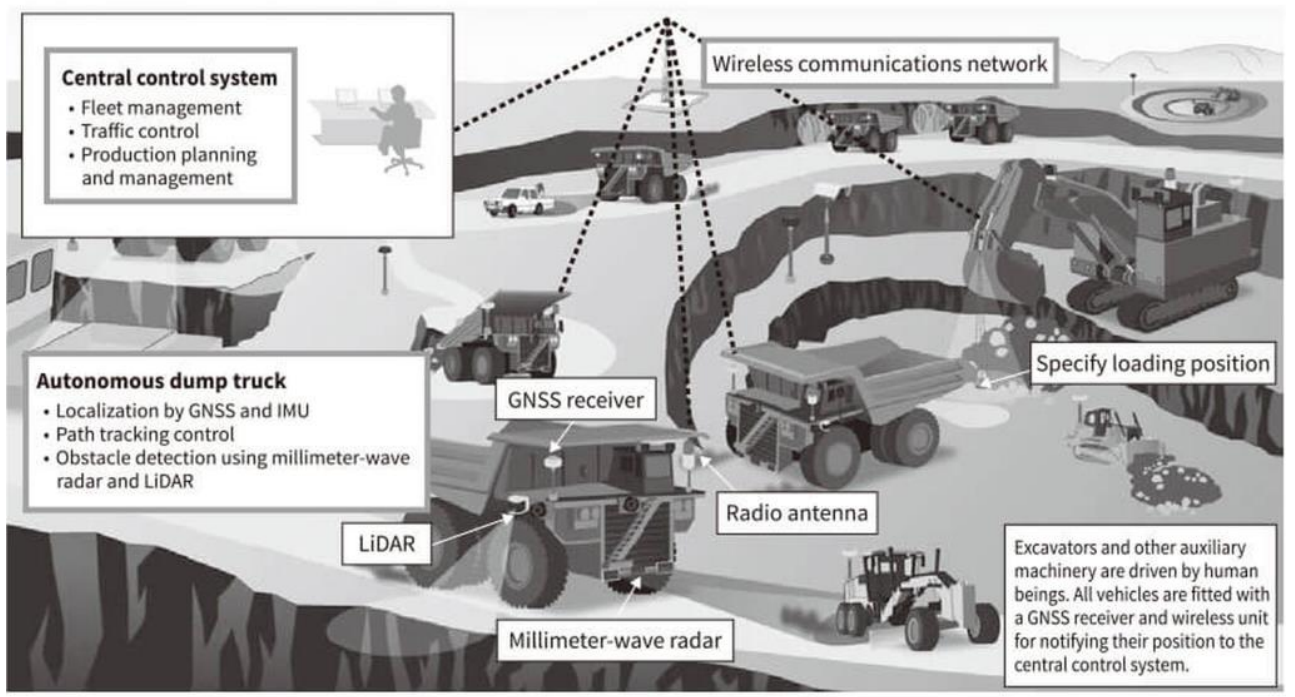

Fig. 1. General view of the quarry with unmanned transport [27]

On this figure: AHS - autonomous haulage system; GNSS - global navigation satellite system; IMU - inertial measurement unit; LiDAR - light detection and ranging

As can be seen from Figure 2, industrial tests of such unmanned vehicles were carried out not at the test site, but in real conditions of the existing open pit.

Further research was aimed at improving the safety level when using unmanned vehicles and improving unmanned technologies.

However, it should be noted that the work aimed at improving the productivity of the excavator-automotive complex, including by improving the organization of work, is essentially sporadic. 


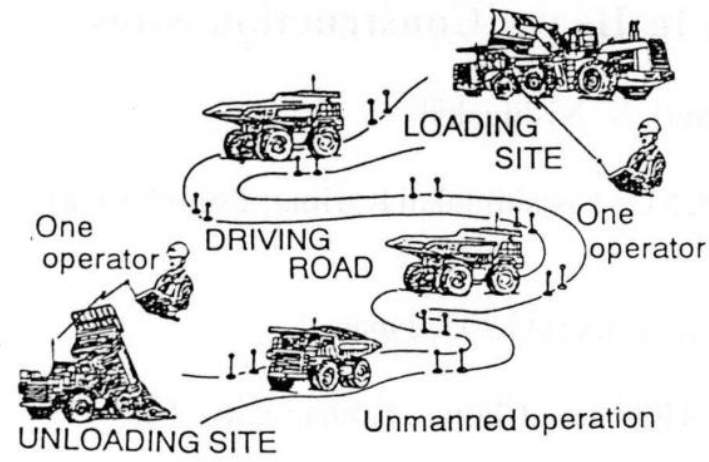

Fig. 2. Structural scheme of operation of the system of autonomous haul trucks [26].

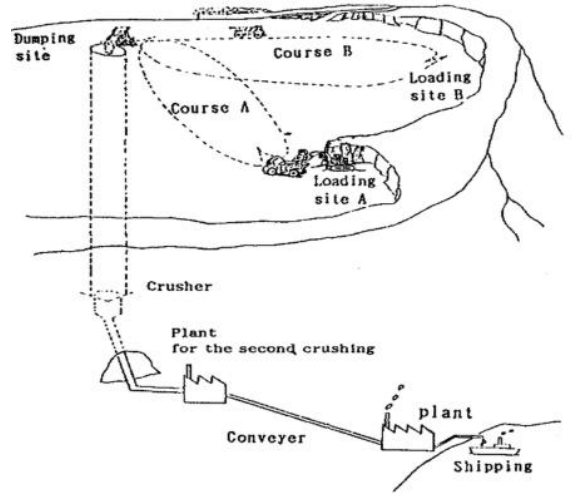

Fig. 3. The structural scheme of the quarry operation with UAVs [20]

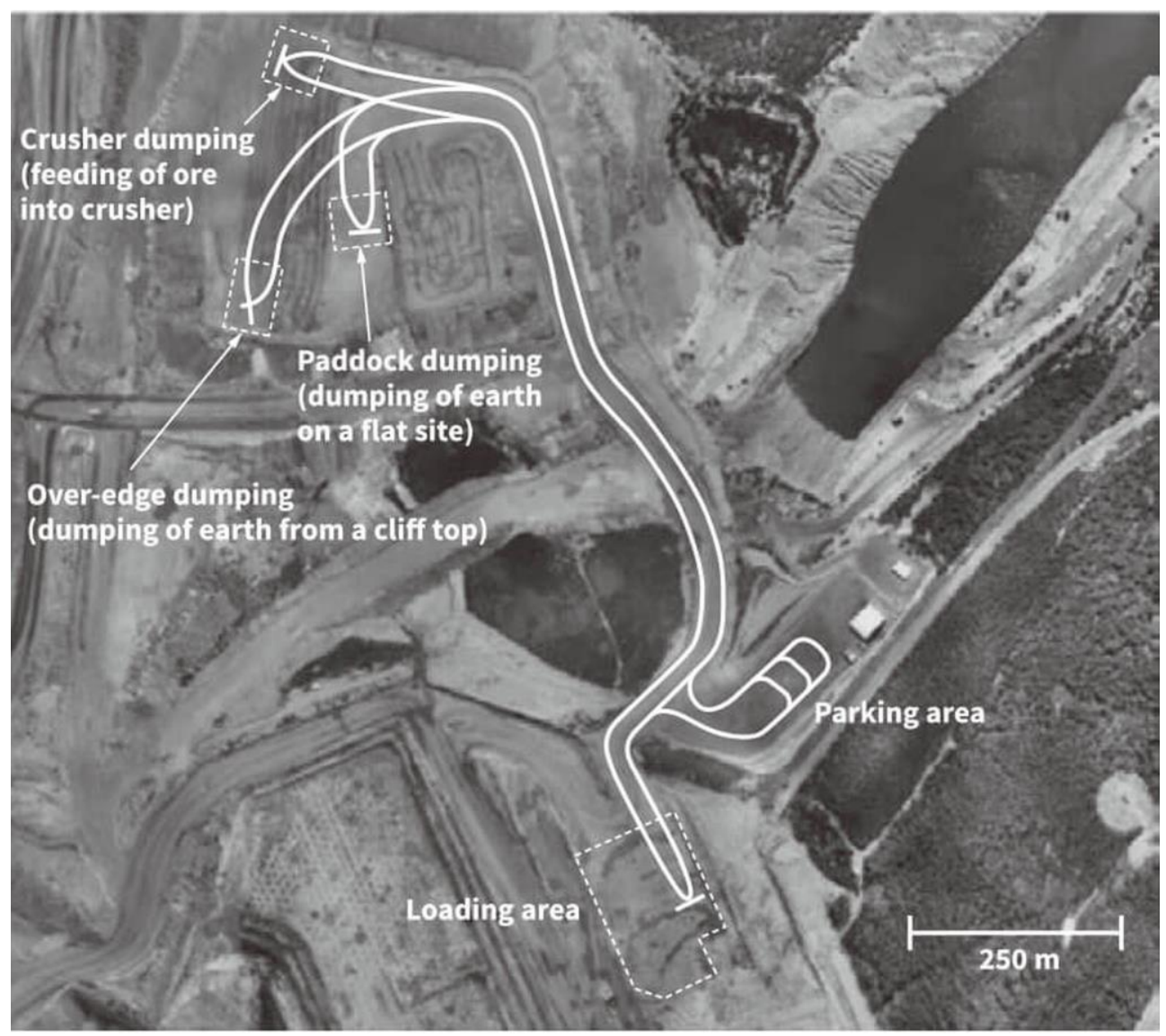

Fig. 4. Scheme of movement of unmanned Hitachi mining haul truck in real conditions at one of the open-pit mines in Australia [27] 


\section{Studying the components of haul truck driving time}

The components of dump truck cycle time have been studied in sufficient detail, including in $[2,3,8,11,12,14,16]$. In fact, their optimization can be reduced to the search for technological solutions contributing to the reduction of one or another component.

Cycle times include:

1) Vehicle loading time. It depends on the bucket capacity of the excavator used, its technological parameters (excavator cycle time), place of location for loading, parameters of the technological scheme (bench height, angle of its slope, etc.), physical and mechanical properties of the loaded rock.

2) Driving time (laden and unladen). Depends on the parameters of the longitudinal profile of the quarry road (slopes), haul truck parameters (traction characteristics, maximum speed, etc.), transportation distance.

3) Unloading time. Depends only on the parameters that characterize the speed of raising/lowering the dump truck body.

4) Maneuvering time in the face. Depends on the qualification of the haul truck driver, the scheme of feeding the vehicle for loading, waiting time.

It is hardly possible to optimize/reduce the driving time in any way without changing the parameters and shape of the trace. Loading time depends on too many factors to talk about optimization without a global recalculation of technology parameters. Maneuvering time in the face can be changed with different schemes of transport feeding for loading with a pass-through scheme it is minimal, with a dead-end scheme it is maximal, with a looping scheme it has an intermediate value. The problem is that almost everywhere used is a dead-end scheme. There are several reasons for this, the main of which is to ensure the minimum width of the working site in order to minimize the current stripping ratio. As the size of haul trucks increases, more and more wide space is required for their turnaround by the looping scheme of feeding. We do not consider the pass-through scheme, since its full functioning requires, firstly, two ramps from the working bench, and secondly, sufficient width of the working site to be placed on it not only the blasted rock mass, but also the transport lane, which width even with single-lane traffic can be $15 \mathrm{~m}$ or more. Therefore, the dead-end turnaround scheme, judging by all appearances, will remain the most widespread in the near future at the open-pit mines.

In recent years, there have appeared projects of motor transport, which either has a minimum turning radius (Fig. 5), or autonomous, working according to the shuttle scheme, i.e. moving forward and backward with the same speed (Fig. 6). It should be said that it is still just projects, i.e. implementation and serial production have not yet begun. In any case, this indicates the high potential of this trend. 


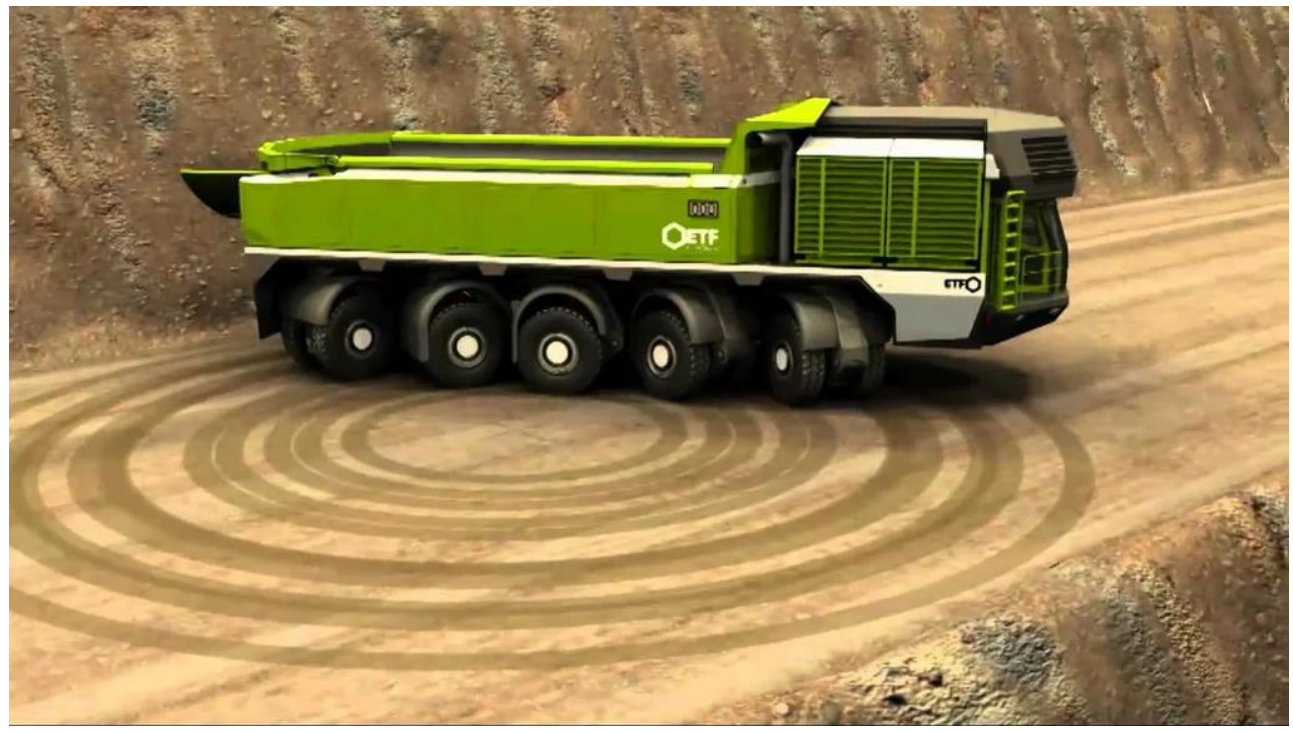

Fig. 5. General view of a dump truck with five driving axles and synchronously turning wheels to minimize the width of the turn area

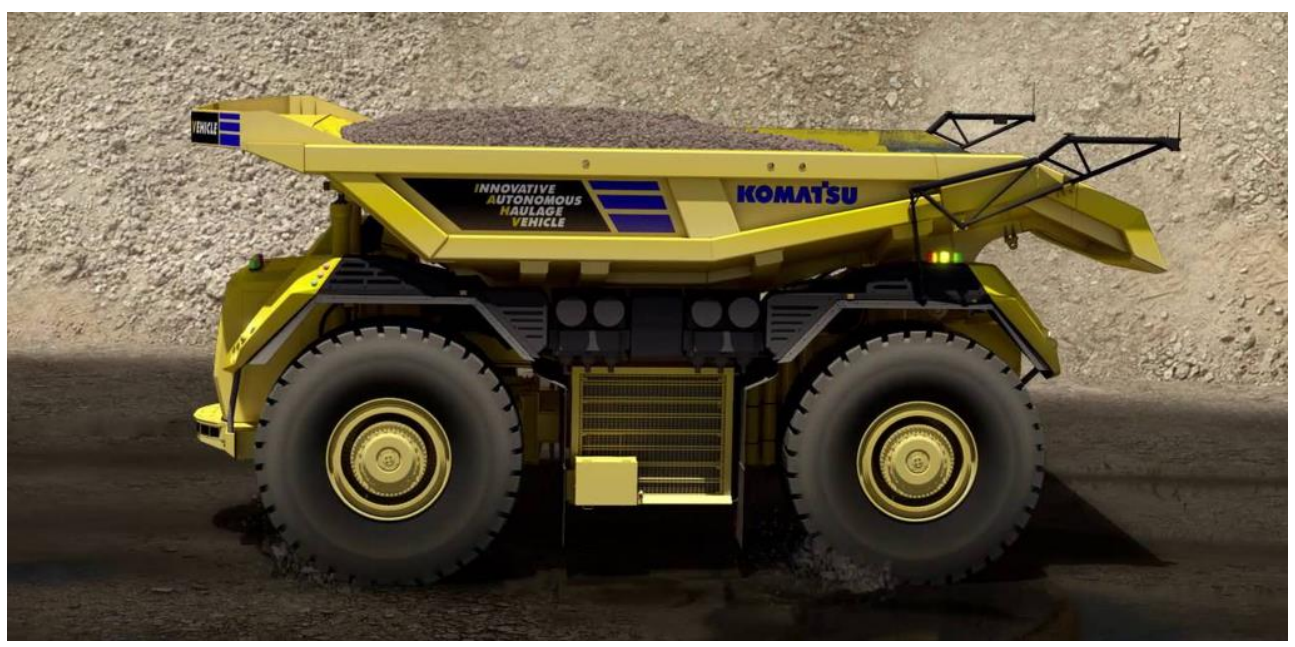

Fig. 6. General view of Komatsu shuttle haul truck

Unfortunately, the information about applicability of such haul trucks in open-pit mining is not yet presented in full and we can only make preliminary conclusions about the potential applicability of this kind of equipment in certain mining-and-geological and geotechnical conditions.

\section{Conclusion}

The data obtained by calculation $[9,12]$, definitely testify to some advantages, which will have an unmanned haul truck when comparing its performance indicators with the open-pit haul trucks of traditional design. Also, it will be necessary to recalculate the parameters of transport technology of open-pit mining because of possible changes in federal norms and 
rules concerning the use of transport and its movement on the face, dumps and other roads in the open pit.

The work is executed within the limits of the complex scientific and technical program of a full innovative cycle "Development and introduction of a complex of technologies in areas of exploration and extraction of solid minerals, maintenance of industrial safety, bioremediation, creation of new products of deep processing from coal raw materials at consecutive decrease in ecological impact on environment and risks for population life" (CSTP "Clean coal - Green Kuzbass") on event 2.5 "Development and creation of an autonomous shuttle-type dump truck with carrying capacity of 220 tons (JUPITER project)", with participation of T.F. Gorbachev Kuzbass State Technical University in terms of research, development and technological works.

\section{References}

1. M. Ehsani, Y. Gao, S. E. Gay, A. Emadi, Modern Electric, Hybrid Electric, Fuel Cell V ehicles (CRC Press, New York, 2005)

2. V.F. Kolesnikov, J. Janočko, Journal of Mining and Geotechnical Engineering, 2(9), 42 (2020)

3. M. Vasilyev, Transportation processes and equipment at open pit mines (Nedra, Moscow, 1986)

4. W. Shabbir, S. Evangelou. "Exclusive Operation Strategy for the Supervisory Control of Series Hybrid Electric Vehicles", IEEE Transactions on Control Systems Technology, (2016)

5. C. von Albrichsfeld, J. Karner, SAE Technical Paper 2009-01-1217 (2009), https://doi.org/10.4271/2009-01-1217.

6. N. Demirel, A. Taghizadeh, S. Khouri, E. Tyuleneva, E3S Web of Conferences 41, 01006 (2018)

7. A.E. Dursun, Scientific Mining Journal, 58(4), 299 (2019)

8. D. Dubinkin, V. Aksenov, M. Tyulenev, S. Markov, Journal of mining and geotechnical engineering, 4(11), 42 (2020)

9. A.C. Özdemir, Scientific Mining Journal, 59(4), 247 (2020)

10. D.M. Dubinkin, Mining Equipment and Electromechanics, 4(150), 59 (2020)

11. M.A. Tyulenev, S.O. Markov, D.M. Dubinkin, V.V. Aksenov, Bulletin KuzSTU. 1(143), 97 (2021)

12. A.V. Katsubin, A.A. Khoreshok, M.A. Tyulenev, S.O. Markov, Mining Informational and Analytical Bulletin, 2020(11), 27 (2020)

13. H. Sis, T.Karaagac, M. Birinci, T. Kiyak, Scientific Mining Journal, 60(1), 31 (2021)

14. A. Strelnikov, S. Markov, L. Rattmann, D. Weber, E3S Web of Conferences, 41, 01003 (2018)

15. F.R. Salmasi, IEEE Transactions on Vehicular Technology 56(5), 2393 (2007)

16. O. Litvin, V. Makarov, A. Strelnikov, E. Tyuleneva, E3S Web of Conferences, 105, 01024 (2019)

17. L. Yu, Chinese Journal of Mechanical Engineering 43(09), 40 (2007)

18. L. Petruccelli, M. Velardocchia, A. Sorniotti, SAE Technical Paper 2003-01-3336 (2003)

19. D. Dubinkin, A. Kulpin, D. Stenin, E3S Web of Conferences, 174, 03015 (2020).

20. T. Tsumura, et al., Journal of the Robotics Society of Japan, 2(3), 33 (1984) 
21. Y. Okawa, T. Nagai, O. Murayama, T. Sudo, SAE Technical Paper Series - Vehicle Control of Unmanned Dump Trucks 1 (1992).

22. H. Oshima, K Kuromoto, Automatic systems and sensor technology of construction equipment (Fluid Power. Proceedings of the Second JHPS International Symposium on Fluid Power. T.Maeda (ed.), CRC Press, London, 1993)

23. O. Hatakcyama, H. Sugiura, The 9th International Symposium on Automationand Robotics in Construction, 849, (1992)

24. S. Iida, S. Yuta, The First Robot Symposium in Japan, 85 (1991)

25. M. Hanawa, N. Hori, The 5th ADVANTY Symposium, 29 (1992)

26. H. Sugiura, S. Yuta, K. Nishide, O. Hatakeyama, S. Nishigaki, Proceedings of the 10th ISARC, 253 (1993)

27. T. Hamada, S. Saito, Hitachi Review 67(1), 87 (2015)

28. D. Mamurekli, C. Aydin, H. Deveci, A.T. Sonmez, Madencilik 35(2), 3 (1996)

29. J. Parreira, J. Meech, Autonomous vs manual haulage trucks - how mine simulation contributes to future haulage system developments (CIM Meeting 2010, Vancouver, BC, Canada, 2010)

30. J.L. Perdomo, Detailed Haul Unit Performance Model (Virginia Polytechnic Institute and State University, Blacksburg, VA, USA, 2001)

31. D. Mamurekli, A computer model for front-end loader and rear-dump truck system. Journal of Mines, Metals and Fuels 51(11-12), 336 (2003)

32. M.W. Lewis, J. Werner, B. Sambirsky, CIM Bulletin 97(1076), 57 (2004)

33. O. Murayama, H. Oshima and T. Nagai, Proceedings of the Intelligent Vehicles '94 Symposium, 25 (1994) 